\title{
Isolation of naproxen from wastewater using carbon-based magnetic adsorbents
}

\author{
Z. İlbay $\cdot$ S. Şahin $\cdot$ Ö. Kerkez $\cdot$ Ş. S. Bayazit
}

Received: 20 May 2014/Revised: 31 December 2014/ Accepted: 28 January 2015/Published online: 17 February 2015

(C) Islamic Azad University (IAU) 2015

\begin{abstract}
Naproxen is one of the mostly used drugs worldwide and is most abundant in wastewater. This study aims to adsorb naproxen from wastewater using magnetically modified carbon-based adsorbents. These adsorbents have very large specific area for naproxen adsorption, and magnetite modification provides easy separation and regeneration. The co-precipitation method was used for magnetic modification. Adsorption process was carried out in batches. The effect of adsorption variables was investigated. Langmuir, Freundlich, and Dubinin-Radushkevich isotherms were applied to the equilibrium data. The maximum adsorption capacities of adsorbents from Langmuir isotherm were found as $20.75 \mathrm{mg} / \mathrm{g}$ for magnetic multiwall carbon nanotubes and $87.79 \mathrm{mg} / \mathrm{g}$ for magnetic activated carbon. Pseudo-first-order kinetic model, pseudosecond-order kinetic model, intra-particle diffusion model, and Bangham model were used for determination of adsorption mechanisms. The rate-limiting step is electron
\end{abstract}

Electronic supplementary material The online version of this article (doi:10.1007/s13762-015-0775-4) contains supplementary material, which is available to authorized users.

Z. İlbay · S. Şahin

Chemical Engineering Department, Engineering Faculty,

Istanbul University, 34320 Istanbul, Turkey

Z. İlbay

Department of Chemical Engineering, Engineering Faculty, Uşak University, Uşak 64200, Turkey

Ö. Kerkez · Ş. S. Bayazit ( $₫)$

Chemical Engineering Department, Engineering

and Architecture Faculty, Beykent University,

Hadımkoruyolu cad. Beykent Universitesi Ayazaga Kampusu,

34396 Sisli, Istanbul, Turkey

e-mail: sahikasena@gmail.com exchange between the adsorbent and adsorbate. Both film diffusion and intra-particle diffusion occur while the adsorption process. $\Delta \mathrm{G}^{\circ}, \Delta \mathrm{S}^{\circ}$, and $\Delta \mathrm{H}^{\circ}$ were calculated for the process.

Keywords Drug · Adsorption - Magnetic separation . Carbon nanotubes $\cdot$ Activated carbon

\section{Introduction}

The usable water resources are decreasing with increasing world population. The irresponsible consumption and environmental pollution accelerate the decrease in resources. The pollutions consist of various industrial wastes and human disposals. Pharmaceuticals are very dangerous pollutants because they are potentially bioactive chemicals in environment (Kümmerer 2001). The pharmaceutical wastes spread to the environment via both industrial and human residuals. The most used pharmaceuticals are analgesics, anti-inflammatory drugs, antipyretic, and antibiotics (Rivera-Utrilla et al. 2013). Especially, the analgesics and antipyretic are mostly used in daily life. Naproxen is one of the most used drugs in the world. Naproxen can be detected in wastewater, surface, and groundwater. Naproxen is released to the water in different ways such as urine and improper disposal (Im et al. 2013). There are different kinds of separation methods for removal of pharmaceutical residuals from water. Adsorption, nanofiltration, and advanced oxidation processes are the few of the most used methods (Bui et al. 2013). The most preferred method is adsorption because this process can be applied easily and the surface properties of adsorbents can be modified according to the adsorbate. This increases adsorption efficiencies. 
Magnetically modified adsorbents are attracting the attention of researchers. $\mathrm{Fe}_{3} \mathrm{O}_{4}$ (magnetite), $\gamma-\mathrm{Fe}_{2} \mathrm{O}_{3}$ (maghemite), and $\alpha-\mathrm{Fe}_{2} \mathrm{O}_{3}$ (hematite) are the most used magnetic particles (Xu et al. 2012). These magnetic nanoparticles can be used alone, and they can be used as composite, with other adsorbents, such as alumina, activated carbon, and carbon nanotubes. Elwakeel (2014) used molybdate-oxoanions-immobilized magnetic chitosan for arsenate adsorption. Namvari and Namazi (2014) were clicked graphene oxide and $\mathrm{Fe} 3 \mathrm{O} 4$ nanoparticles together for removal of methylene blue and Congo red. Qu et al. (2007) loaded $\mathrm{Fe}_{3} \mathrm{O}_{4}$ nanoparticles on multi-walled carbon nanotubes (MWCNTs). And they used MWCNT/nano$\mathrm{Fe}_{3} \mathrm{O}_{4}$ for electrochemical sensor. Do et al. (2011) produced activated carbon/ $/ \mathrm{Fe}_{3} \mathrm{O}_{4}$ nanocomposite for methyl orange adsorption. Yang et al. (2014) prepared iron oxidehydroxyapatite nanocomposites for lead adsorption. Magnetic nanoparticles have large specific surface area and small diffusion resistance (Shariati et al. 2011). The separation of adsorbents from the heterogeneous adsorption mixture after the equilibrium can be very difficult. The magnetic adsorbents can be used to overcome this problem (Bayazit and Kerkez 2014). Different adsorbents were used for naproxen adsorption. Hasan et al. (2013) prepared metal-organic frameworks (MIL-101) for this purpose and functionalized this material with acidic and basic groups. Baccar et al. (2012) prepared activated carbon from olive-waste cakes, and they adsorbed ibuprofen, ketoprofen, naproxen, and diclofenac onto this low-cost adsorbent. Attia et al. (2013) used zeolite-coated magnetic nanoparticles for removal of pharmaceutical compounds. Domínguez-Vargas et al. (2013) adsorbed carbamazepine, naproxen, and trimethoprim on Amberlite XAD-7. Lü et al. (2012) used three different activated carbons for removal of trace naproxen from water. The activated carbons are coal carbon, apricot carbon, and coconut carbon.

The naproxen was adsorbed on a wide variety of adsorbents, in previous studies. Also, different kinds of magnetic nanoparticles were investigated. However, magnetically modified multi-wall carbon nanotubes and activated carbon have not been investigated previously. The high adsorption capacities of multi-wall carbon nanotubes and activated carbon are known. These adsorbents were modified with magnetite and hence became magnetically separable. The objectives of this study were to prepare magnetic nanocomposites: magnetite + MWCNT and magnetite $+\mathrm{AC}$, and to investigate the effects of adsorption variables such as adsorbent amount, contact time, initial $\mathrm{pH}$, ionic strength, temperature, and naproxen concentrations on adsorptive removal of naproxen.
This work was realized in Chemical Engineering Laboratory, Istanbul University, in January 2014.

\section{Materials and methods}

Materials

MWCNTs were purchased from Shenzhen NANO Tech. Port. Co. Ltd. (China). The length of MWCNTs is $1-2 \mu \mathrm{m}$, and the purity is $>98 \%$. The specific surface area is $100-120 \mathrm{~m}^{2} / \mathrm{g}$. The activated carbon (AC), $\mathrm{FeCl}_{3} \cdot 6 \mathrm{H}_{2} \mathrm{O}$, $\mathrm{FeSO}_{4} \cdot 7 \mathrm{H}_{2} \mathrm{O}$, and ammonia solution $(25 \%)$ were purchased from Merck. And naproxen was obtained from Sigma-Aldrich.

Methods

\section{Preparation of magnetic MWCNT and magnetic AC composites}

The co-precipitation method was used for preparing magnetic MWCNT composite. The MWCNTs were kept in an oven at $350{ }^{\circ} \mathrm{C}$ for $30 \mathrm{~min}$, for cleaning the amorphous carbon. The catalyst particles in MWCNTs have been cleared by oxidizing with concentrated $\mathrm{HNO}_{3}$ in an ultrasonic bath for $100 \mathrm{~min}$, and then washed with deionized water till the $\mathrm{pH}$ reached 7 and, then, dried at $60{ }^{\circ} \mathrm{C}$. The mixture of $\mathrm{Fe}$ (II) and $\mathrm{Fe}$ (III) was prepared. The preparation ratio is 1:2. The mixture and the MWCNTs were suspended in $200 \mathrm{ml}$ of deionized water. The mass ratio of (MWCNTs: $\mathrm{Fe}^{2+}+\mathrm{Fe}^{3+}$ ) must be 1:4. The co-precipitation method was carried out at ultrasonic bath. $8 \mathrm{M} \mathrm{NH}_{4} \mathrm{OH}$ solution was used as precipitation agent. This procedure was carried on till the $\mathrm{pH}$ of the mixture reached 11-12. The co-precipitation reaction of $\mathrm{Fe}_{3} \mathrm{O}_{4}$ is:

$\mathrm{Fe}^{2+}+2 \mathrm{Fe}^{3+}+8 \mathrm{OH}^{-} \rightarrow \mathrm{Fe}_{3} \mathrm{O}_{4} \downarrow+4 \mathrm{H}_{2} \mathrm{O}$

The process was continued for $30 \mathrm{~min}$ at $50{ }^{\circ} \mathrm{C}$ under mechanical stirring. The magnetic adsorbent separated from the solution by $\mathrm{NdFeB}$ magnet and was washed with deionized water and ethanol. The M-MWCNTs were dried at $60{ }^{\circ} \mathrm{C}$ in a vacuum oven (Qu et al. 2007). Magnetically modified activated carbon (M-AC) was produced as if M-MWCNTs (Bayazit and Kerkez 2014).

\section{The characterization of magnetic nanoparticles}

The surface characterizations of M-MWCNT and $\mathrm{M}$-AC were made by X-ray diffraction (XRD) [Rigaku D/Max-2200 diffractometer $\left(\mathrm{Cu} \quad \mathrm{K}_{\alpha}\right.$ radiation with 
$\lambda=0.15418 \mathrm{~nm}$ )], thermogravimetric analysis (TGA) (Shimadzu TG-50A), and scanning electron microscopy (SEM) (FE-SEM, FEI Quanta FEG 450 at $30 \mathrm{kV}$ and $200,000 \mathrm{mag}$ ) analysis. The solid addition method was used for determining the point of zero charges $\left(\mathrm{pH}_{\mathrm{pzc}}\right)$ of the adsorbents (Ai et al. 2011). In this method, the adsorbents were mixed with $\mathrm{KNO}_{3}$ solution at different $\mathrm{pH}$ values $(2-11)$. The mixtures were shaken for $48 \mathrm{~h}$. After the adsorbents removed from the solution, the final $\mathrm{pH}$ values were analyzed using $\mathrm{pH}$ meter (Mettler Toledo S-20 K). The $\Delta \mathrm{pH}=\mathrm{pH}_{\mathrm{f}}-\mathrm{pH}_{\mathrm{i}}$ and $\mathrm{pH}_{\mathrm{i}}$ plot was drawn for determining the $\mathrm{pH}_{\mathrm{pzc}}$. The intersection point of $\Delta \mathrm{pH}=0$ and curve gave the $\mathrm{pH}_{\mathrm{pzc}}$ (Ai et al. 2011). FTIR (Bruker Alpha spectrometer) analyses were performed before and after the naproxen adsorption.

\section{Adsorption experiments}

The adsorption experiments were carried out in batch mode by mixing a specific amount of adsorbent and $10 \mathrm{~mL}$ of naproxen solution in the stoppered conical flask under constant shaking $(120 \mathrm{rpm})$ in a thermostat shaker. The effects of contact time, amount of adsorbent, initial naproxen concentration, $\mathrm{pH}$, and temperature of the naproxen solutions were investigated.

The equilibrium time of adsorption was between 0-240 min. The amount of adsorbent was chosen as $3 \mathrm{mg}$, and the naproxen solution concentration was $10 \mathrm{mg} / \mathrm{L}$. The adsorbent amount range was chosen as $1-10 \mathrm{mg}$. The concentration range was chosen as $1-30 \mathrm{mg} / \mathrm{L}$ for the effect of initial naproxen concentration experiments. And at these concentration intervals, the temperature effect was investigated. $20^{\circ} \mathrm{C}, 30^{\circ} \mathrm{C}, 40{ }^{\circ} \mathrm{C}$, and $50{ }^{\circ} \mathrm{C}$ were chosen for determining the temperature effect and thermodynamics calculations. Five different $\mathrm{pH}$ values were used to investigate the $\mathrm{pH}$ effect; these values were between 3 and 11. The $0.1 \mathrm{M} \mathrm{NaOH}$ and $0.1 \mathrm{M} \mathrm{H}_{2} \mathrm{SO}_{4}$ were used for $\mathrm{pH}$ adjusting.

The effect of ionic strength was investigated adding different concentrations of sodium phosphate (1-100 m$\mathrm{mol})$ into the naproxen solution $(10 \mathrm{mg} / \mathrm{L})$.

The naproxen concentration was analyzed by UV-Vis spectrophotometer (PG Instruments) at $230 \mathrm{~nm}$ (Hasan et al. 2012). The uptakes of adsorbents $\left(\mathrm{Q}_{\mathrm{e}}, \mathrm{mg} / \mathrm{g}\right)$ were calculated by the Eq. 2 .

$Q_{\mathrm{e}}=\frac{\left(C_{0}-C_{\mathrm{e}}\right) \cdot V}{m}$

where $C_{0}$ and $C_{\mathrm{e}}(\mathrm{mg} / \mathrm{L})$ are initial concentration and the equilibrium concentration of naproxen, respectively. $V(\mathrm{~L})$ is the volume of the solution. $m(\mathrm{~g})$ is the amount of adsorbent.

\section{Results and discussion}

The characterization of M-MWCNT and M-AC

The synthesized materials were characterized using XRD, TGA, SEM, and $\mathrm{pH}_{\mathrm{zpc}}$. The XRD patterns of MWCNT, M-MWCNT, AC, and M-AC can be seen in Supporting Fig. 1(a) and (b) (Bayazit and Kerkez 2014). The TGA plots of composites are given in Supporting Fig. 2. The loading ratios of MWCNT, AC, and $\mathrm{Fe}_{3} \mathrm{O}_{4}$ were determined using TGA values. The magnetite ratios are $51.49 \%$ of M-MWCNT and $50.57 \%$ of M-AC. The SEM images are shown in Supporting Fig. 3. The $\mathrm{pH}_{\mathrm{zpc}}$ graphic is in Supporting Fig. 4. The FTIR spectra are in Supporting Fig. 5. The spectra before naproxen adsorption are shown in Supp. Figure 5 (a and c), and spectra after naproxen adsorption are in Supp. Figure 5 (b and d). Fe-O peak can be seen at approximately $620 \mathrm{~cm}^{-1}$ in all spectra. When the adsorbent is M-AC, the alkyl C-H stretching peaks at 2,851 and 2,937 $\mathrm{cm}^{-1}$ disappeared (Supp. Figure 5 a and c). The naproxen adsorption effects can clearly be seen in M-MWCNT spectra. The N-H stretching vibration at approximately $3,401 \mathrm{~cm}^{-1}$ is shown in Supp. Figure 5 (d). The characteristics peaks of naproxen such as 1,375, 1,430, and $1,605,1,462 \mathrm{~cm}^{-1}$ can be seen in Supp. Figure 5 (d) (Hosseini et al. 2014).

\section{Batch adsorption experiments}

\section{The effect of amount of adsorbent}

The effect of amount of adsorbent on naproxen adsorption of M-MWCNT and M-AC was investigated. The results can be seen in Fig. 1. The results are given as uptake of

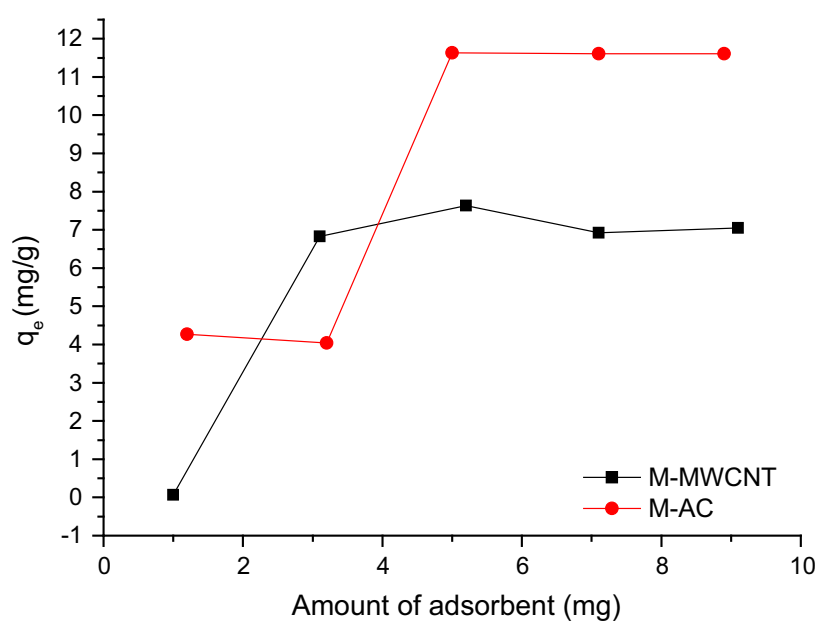

Fig. 1 Effects of amount of adsorbent on naproxen adsorption 
naproxen. The initial naproxen concentration was chosen as $10 \mathrm{mg} / \mathrm{L}$. The adsorption capacity of M-MWCNT is $7.5 \mathrm{mg} / \mathrm{g}$, while the amount of adsorbent is above $5 \mathrm{mg}$, and the maximum adsorption percentage of naproxen is $47.58 \%$ at $7.1 \mathrm{mg}$ of M-MWCNT. The naproxen adsorption capacity of M-AC is $79.77 \%(11.61 \mathrm{mg} / \mathrm{g})$. The adsorption capacity of M-AC is greater than M-MWCNT.

\section{The effect of contact time}

The constants of the effect of contact time experiments are as follows: the concentration of naproxen solution $10 \mathrm{mg} /$ $\mathrm{L}$, the adsorbent dose $3 \mathrm{mg}$, and the solution $\mathrm{pH}$ 5. The time duration of the experiment is $0-240 \mathrm{~min}$. The results of the effect of contact time on naproxen adsorption are given in Fig. 2. Adsorption takes place rapidly for both of the adsorbents at the first $30 \mathrm{~min}$. Then, the adsorption rate slowed, and after $150 \mathrm{~min}$, the system reached equilibrium. The results of the contact time experiment were used to calculate the adsorption kinetic models, pseudo-first-order model, pseudo-second-order model, Weber-Morris intraparticle diffusion model, and Bangham model.

\section{The effect of initial pH of naproxen solutions and ionic strength}

The effect of solution $\mathrm{pH}$ on naproxen adsorption was investigated. The results of $\mathrm{pH}$ effects experiments are given in Fig. 3. The $\mathrm{pH}$ range is $3-11$. The naproxen concentration is $10 \mathrm{mg} / \mathrm{L}$. As shown in Fig. 3, the increasing $\mathrm{pH}$ leads to decrease in adsorption uptake. The yield of naproxen adsorption on M-MWCNT decreased from $67.20 \%(\mathrm{pH} \mathrm{3})$ to $9.74 \%(\mathrm{pH} \mathrm{11)}$. And the yield of naproxen adsorption on M-AC decreased from $87.26 \%$ (pH 3) to $15.29 \%(\mathrm{pH} 11)$. It is seen that the acidic $\mathrm{pH}$ is

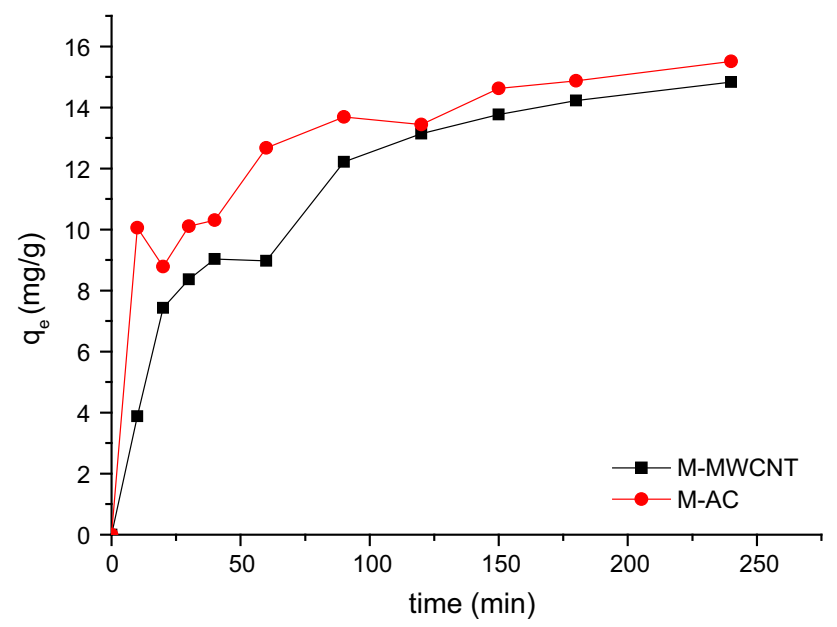

Fig. 2 Effects of contact time on naproxen adsorption

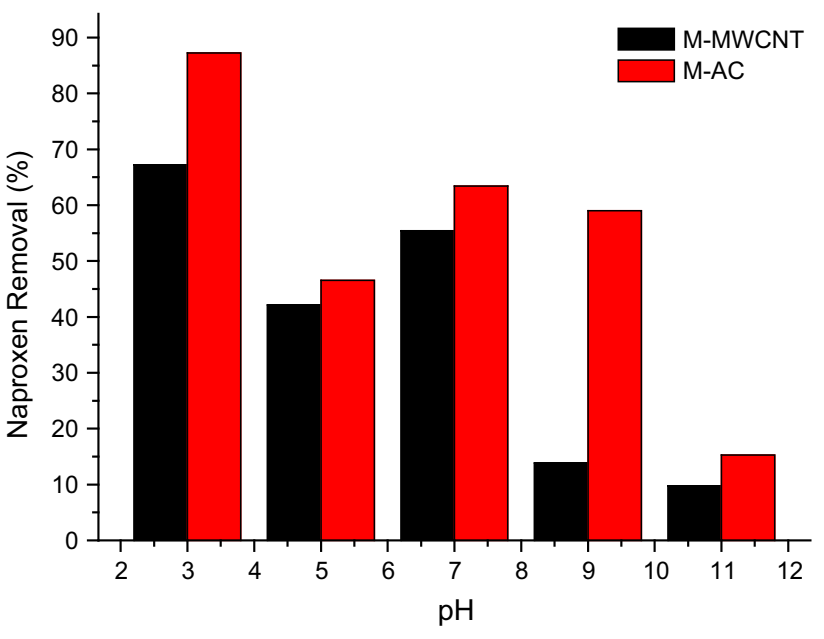

Fig. 3 Effects of solution $\mathrm{pH}$ on naproxen adsorption

more suitable for naproxen adsorption. The adsorption efficiency decreased with the increasing $\mathrm{pH}$. DomínguezVargas et al. (2013) reported the same relation between the $\mathrm{pH}$ of naproxen solution and adsorption uptake. This behavior can be explained using the terms of $\mathrm{p} K_{\mathrm{a}}$ of naproxen and $\mathrm{pH}_{\mathrm{zpc}}$ of adsorbents. The $\mathrm{pKa}$ value of naproxen is 4.15 (Baccar et al. 2012). If the $\mathrm{p} K_{\mathrm{a}}>\mathrm{pH}$, naproxen is a neutral compound and non-electrostatic interactions occur. If $\mathrm{pH}>\mathrm{p} K_{\mathrm{a}}$, the naproxen is negatively charged.

It is well known that the surface of carbon is neutral at $\mathrm{pH}=\mathrm{pH}_{\mathrm{zpc}}$, negatively charged at $\mathrm{pH}>\mathrm{pH}_{\mathrm{zpc}}$, and positively charged at $\mathrm{pH}<\mathrm{pH}_{\mathrm{zpc}}$ (Baccar et al. 2012). As shown in Supporting Fig. 4, the $\mathrm{pH}_{\mathrm{zpc}}$ values of M-AC and M-MWCNT are 6.8-7. It means the surface of adsorbents at acidic medium charges positively. In addition, naproxen is neutral at acidic medium. Therefore, the adsorption occurs by hydrogen bonding and van der Waals interaction (Domínguez et al. 2011). At the basic medium, both of the naproxen and the surface of adsorbent are negatively charged and the electrostatic repulsion occurs. This leads to decreasing adsorption uptake (Baccar et al. 2012).

The ionic strength effect is shown in Supp. Figure 6. The ionic strength was modified by $\mathrm{Na}_{3} \mathrm{PO}_{4}$. The concentrations of $\mathrm{Na}_{3} \mathrm{PO}_{4}$ vary between 1 and $100 \mathrm{mmol}$. As shown in Supp. Figure 6, the naproxen adsorption capacity decreases with the increasing sodium phosphate concentration. The adsorption percentage of M-AC decreased from 13 to $4.28 \%$. For M-MWCNT, these values were betweeen 12.52 and $6.98 \%$.

\section{Adsorption isotherms}

The adsorption isotherm data were obtained at four different temperatures $(293,303,313$, and $323 \mathrm{~K})$. The concentration range is $1-30 \mathrm{mg} / \mathrm{L}$. The adsorption equilibrium 

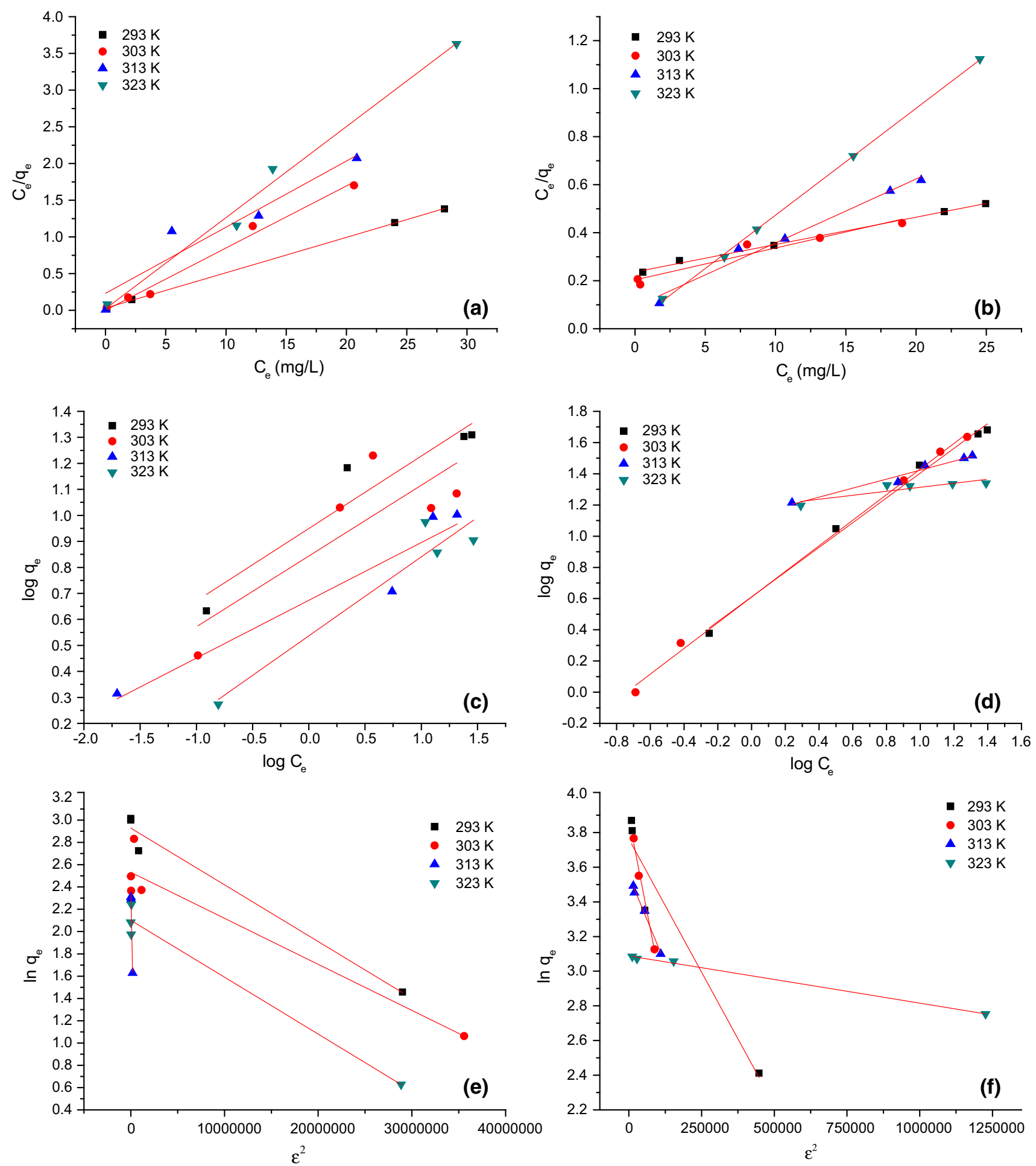

Fig. 4 Langmuir isotherm plots for a M-MWCNT and b M- AC; Freundlich isotherm plots for $\mathbf{c}$ M-MWCNT and d M- AC; DubininRadushkevich isotherm plots for e M-MWCNT and f M-AC 
Table 1 Langmuir, Freundlich, and D-R isotherm parameters of naproxen adsorption on M-MWCNT and M-AC

\begin{tabular}{|c|c|c|c|c|c|c|c|c|}
\hline \multirow[t]{2}{*}{ Isotherm parameters } & \multicolumn{4}{|c|}{ M-MWCNT } & \multicolumn{4}{|l|}{ M-AC } \\
\hline & $293 \mathrm{~K}$ & $303 \mathrm{~K}$ & $313 \mathrm{~K}$ & $323 \mathrm{~K}$ & $293 \mathrm{~K}$ & $303 \mathrm{~K}$ & $313 \mathrm{~K}$ & $323 \mathrm{~K}$ \\
\hline \multicolumn{9}{|l|}{ Langmuir } \\
\hline$K_{\mathrm{L}}(\mathrm{L} / \mathrm{mg})$ & 1.57 & 30.57 & 0.38 & 8.06 & 0.05 & 0.06 & 0.29 & 1.60 \\
\hline$Q_{m}(\mathrm{mg} / \mathrm{g})$ & 20.75 & 11.81 & 11.09 & 8.06 & 87.79 & 75.02 & 37.58 & 22.46 \\
\hline$R^{2}$ & 0.99 & 0.98 & 0.87 & 0.98 & 0.99 & 0.93 & 0.98 & 0.99 \\
\hline \multicolumn{9}{|l|}{ Freundlich } \\
\hline $1 / n$ & 0.28 & 0.27 & 0.22 & 0.31 & 0.79 & 0.82 & 0.28 & 0.13 \\
\hline$n$ & 3.57 & 3.70 & 4.55 & 3.23 & 1.27 & 1.22 & 3.57 & 7.69 \\
\hline$K_{\mathrm{f}}(\mathrm{L} / \mathrm{mg})$ & 8.90 & 6.97 & 4.71 & 3.44 & 4.08 & 4.07 & 13.64 & 15.31 \\
\hline$R^{2}$ & 0.87 & 0.59 & 0.88 & 0.89 & 0.99 & 0.99 & 0.95 & 0.72 \\
\hline \multicolumn{9}{|l|}{ D-R } \\
\hline$q_{\mathrm{s}}$ & 18.71 & 12.58 & 11.08 & 8.18 & 43.07 & 48.55 & 34.81 & 21.99 \\
\hline$E$ & 3,132 & 3,477 & 350.11 & 3,128 & 403.24 & 240.02 & 351.19 & 1,354 \\
\hline$R^{2}$ & 0.97 & 0.92 & 0.99 & 0.97 & 0.94 & 0.99 & 0.99 & 0.99 \\
\hline
\end{tabular}

data were analyzed with Langmuir, Freundlich, and Dubinin-Radushkevich isotherms. The linearized Langmuir isotherm (Langmuir 1918) (Eq. 3) was applied to the experimental data.

$\frac{C_{\mathrm{e}}}{q_{\mathrm{e}}}=\frac{1}{\left(K_{L} Q_{m}\right)}+\frac{1}{Q_{m}} C_{\mathrm{e}}$

The slope and the intercept of the $\left(C_{\mathrm{e}} / q_{\mathrm{e}}-C_{\mathrm{e}}\right)$ plot provide $K_{\mathrm{L}}(\mathrm{L} / \mathrm{mg})$ and $Q_{m}(\mathrm{mg} / \mathrm{g})$. M-AC and M-MWCNT followed the Langmuir isotherm. The Langmuir isotherm parameters are given in Table 1 and Fig. $4 \mathrm{a}$ and b. It was seen that the theoretical adsorption capacities $\left(Q_{m}\right)$ of M-MWCNT decreased with increasing temperature, $20.75 \mathrm{mg} / \mathrm{g}$ at $293 \mathrm{~K}$ and $8.06 \mathrm{mg} / \mathrm{g}$ at $323 \mathrm{~K}$. The same behavior was observed for M-AC. The $Q_{m}$ value is $87.79 \mathrm{mg} / \mathrm{g}$ at $293 \mathrm{~K}$ and $22.46 \mathrm{mg} / \mathrm{g}$ at $323 \mathrm{~K}$. The adsorption mechanism depends on the Langmuir isotherm can be explained that the adsorption performs at monolayer and finite number of adsorption sites. Baccar et al. (2012) used activated carbon prepared from agricultural byproduct (olive-waste cakes) to adsorb pharmaceuticals, and their theoretical adsorption capacity is $39.5 \mathrm{mg} / \mathrm{g}$. Hasan et al. (2013) used metal organic frameworks for naproxen adsorption, and they reached $131 \mathrm{mg} / \mathrm{g}$ of adsorption capacity, and when they used activated carbon, they obtained $81 \mathrm{mg} / \mathrm{g}$ of naproxen adsorption capacity. Ghosh et al. (2013) used superparamagnetic $\mathrm{Fe} 3 \mathrm{O} 4$ nanoparticles bearing aminated $\beta$-cyclodextrin. Their obtained adsorption capacity was $1.656 \mathrm{mg} / \mathrm{g}$.
The second isotherm used in this study is linearized Freundlich isotherm (Freundlich 1906).

$\ln Q_{\mathrm{e}}=\ln K_{\mathrm{f}}+(1 / n) \ln C_{\mathrm{e}}$

In Eq. $4, K_{\mathrm{f}}$ is the adsorption constant and $\mathrm{n}$ is a constant about the capacity and intensity of adsorption. The Freundlich isotherm results are given in Table 1 and Fig. $4 \mathrm{c}$ and $\mathrm{d}$. The fitting ratio of M-MWCNT is lower than of M-AC. In the Freundlich parameters, if $1 / n$ closes to zero and $n$ is higher than unity, it shows the favorable physical process (Ghaedi et al. 2012). According to the explanation, adsorption on M-MWCNT and M-AC shows the favorable physical process.

The last adsorption isotherm applied in this study is Dubinin-Radushkevich isotherm (Eq. 5) (Dubinin 1947).

$\ln q_{\mathrm{e}}=\ln Q_{s}-B \varepsilon^{2}$

$\varepsilon=\mathrm{RT} \ln \left(1+\frac{1}{C_{\mathrm{e}}}\right)$

$E=\frac{1}{\sqrt{2 B}}$

where $Q_{\mathrm{s}}$ is the theoretical monolayer saturation capacity $(\mathrm{mg} / \mathrm{g}), B$ is the Dubinin-Radushkevich model constant $\left(\mathrm{mol}^{2} / \mathrm{kJ}^{2}\right) . \varepsilon$ is the Polanyi potential (Eq. 6). $E$ is the mean adsorption energy (kJ/mol) (Eq. 7) (Amin 2009). The results of D-R isotherm are shown in Table 1 and Fig. 4e and $\mathrm{f}$. The naproxen adsorption for both of the adsorbents is fitted to the D-R isotherm. It can be seen from the 
Table 2 Pseudo-first-order model, pseudo-second-order model, intra-particle diffusion model, and Bangham model parameters

\begin{tabular}{lcc}
\hline Kinetic parameters & M-MWCNT & M-AC \\
\hline Pseudo-first-order model & & \\
$k_{1}(\mathrm{~L} / \mathrm{min})$ & 0.007 & 0.006 \\
$q_{\mathrm{e}}(\mathrm{mg} / \mathrm{g})$ & 2.91 & 2.41 \\
$R^{2}$ & 0.98 & 0.94 \\
Pseudo-second-order model & & \\
$k_{2}(\mathrm{~g} \mathrm{mg} / \mathrm{min})$ & 0.002 & 0.004 \\
$q_{\mathrm{e}}(\mathrm{mg} / \mathrm{g})$ & 16.95 & 16.29 \\
$R^{2}$ & 0.99 & 0.99 \\
Intra-particle diffusion model & & \\
$k_{\mathrm{i}}(\mathrm{mg} / \mathrm{g} / \mathrm{min})$ & 0.84 & 0.55 \\
$C$ & 3.15 & 7.47 \\
$R^{2}$ & 0.91 & 0.89 \\
Bangham model & & 0.28 \\
$\alpha$ & 0.37 & 0.004 \\
$k_{0}\left(\times 10^{-3} \mathrm{~mL} /(\mathrm{g} / \mathrm{L})\right)$ & 0.003 & 0.95 \\
$R^{2}$ & 0.95 & \\
\hline
\end{tabular}

adsorption energies in Table 1 that the chemical adsorption occurred between the adsorbents and naproxen.

\section{Adsorption kinetics}

The pseudo-first-order kinetic model (Lagergren 1898), pseudo-second-order kinetic model (Ho and McKay 1999), Weber-Morris intra-particle diffusion model (Weber 1963), and Bangham model (Nethaji et al. 2013) were applied to the kinetic data. The results are given in Table 2 and Fig. 5a-d.

The pseudo-first-order kinetic model was proposed by Lagergren for analyzing the kinetics of adsorption. It can be expressed in its linear form as (Eq. 8):

$\log \left(q_{\mathrm{e}}-q_{t}\right)=\log q_{\mathrm{e}}+\frac{k_{1}}{2.303} t$

where $q_{\mathrm{e}}(\mathrm{mg} / \mathrm{g})$ and $q_{\mathrm{t}}(\mathrm{mg} / \mathrm{g})$ are the amounts of adsorbed adsorbate at equilibrium and at time $t$, respectively, and $k_{1}$ $\left(\mathrm{min}^{-1}\right)$ is the rate constant of pseudo-first-order adsorption (Amin 2009). The adsorption mechanism of both adsorbents is fitted to pseudo-first-order kinetic model. Generally, pseudo-first-order kinetic model is used for explaining the first step of adsorption (Amin 2009). $\frac{t}{q_{t}}=\frac{1}{k_{2} q_{\mathrm{e}}^{2}}+\frac{1}{q_{\mathrm{e}}} t$

Eq. 9 describes the pseudo-second-order kinetic model. In Eq. $9, k_{2}(\mathrm{~g} \mathrm{mg} / \mathrm{min})$ is the rate constant and $q_{\mathrm{t}}(\mathrm{mg} / \mathrm{g})$ is the adsorption uptake at time $t$. The slope of the $t / q_{t}-\mathrm{t}$ plot gives the $q_{\mathrm{e}}$, adsorption capacity, and the intercept of the plot gives $k_{2}$. Both of the adsorbents were fitted to pseudosecond-order kinetic model. The rate-limiting step is the electron exchange between naproxen and adsorbent surface (Qiu et al. 2009). The adsorption of naproxen on M-AC and M-MWCNT was a chemisorption process involving valence force through the sharing or exchange of electron between adsorbate and adsorbent species (Nethaji et al. 2013).

$Q_{t}=k_{i} t^{0.5}+C$

Eq. 10 describes the intra-particle diffusion model. In Eq. $10, k_{\mathrm{i}}(\mathrm{mg} / \mathrm{g} / \mathrm{min})$ is the diffusion constant. Both of the adsorbents fit to this diffusion model. If the $C=0$, the adsorption carries on intra-particle diffusion, but if $C \neq 0$, the adsorption carries on both film diffusion and intraparticle diffusion. The adsorption mechanism performs both film diffusion and intra-particle diffusion (Bayazit and Kerkez 2014).

Bangham equation is used for determining the slowest step in the adsorption process (Nethaji et al. 2013) (Eq. 11).

$\log \log \left(\frac{C_{0}}{C_{0}-Q_{t} m}\right)=\log \left(\frac{k_{0} m}{2.303 V}\right)+\alpha \log t$

Bangham model is given in Eq. 11 . In the equation, $C_{0}$ $(\mathrm{mg} / \mathrm{L})$ is the initial concentration of naproxen in the solution, $V(\mathrm{~L})$ is the volume of the solution, $m(\mathrm{~g} / \mathrm{L})$ is the weight of the adsorbent used per liter of the solution, $q_{t}$ $(\mathrm{mg} / \mathrm{g})$ is the amount of the adsorbent retained at time $t$, and $\alpha$ and $k_{\mathrm{o}}$ are constants. Both of the adsorbents fit to Bangham model. Linear plot shows that the diffusion of adsorbate into the pores of adsorbents is not the only ratecontrolling step (Tütem et al. 1998).

\section{Thermodynamic study}

The thermodynamic parameters are given in Supp. Table 1, and the van't Hoff plots are given in Supp. Figure 7. $\Delta \mathrm{G}^{\circ}$, $\Delta \mathrm{S}^{\circ}$, and $\Delta \mathrm{H}^{\circ}$ were calculated.

$\Delta G^{\circ}=-R T \ln K_{\mathrm{d}}$ 

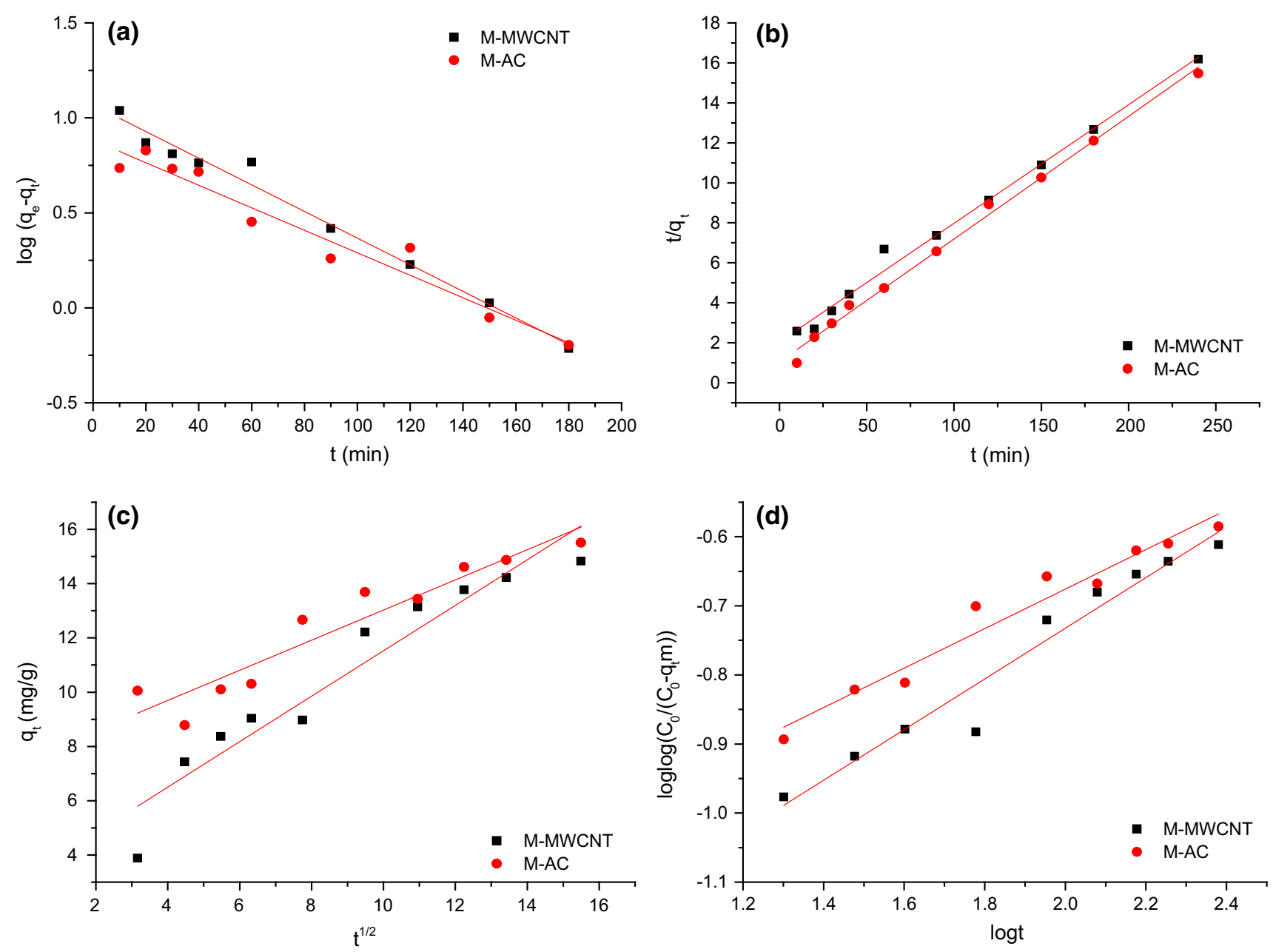

Fig. 5 Adsorption kinetic models; a pseudo-first-order kinetic model plots, b pseudo-second-order kinetic model plots, c intra-particle diffusion model plots, and $\mathbf{d}$ Bangham models plots

The Gibbs free energy changes in the adsorption were determined using Eq. 9. $K_{\mathrm{d}}=q_{\mathrm{e}} / C_{\mathrm{e}}$. The enthalpy changes $\left(\Delta \mathrm{H}^{\circ}\right)$ and entropy changes $\left(\Delta \mathrm{S}^{\circ}\right)$ were calculated using van't Hoff equation (Eq. 10).

$\ln K_{\mathrm{d}}=\Delta S^{\circ} / R-\Delta H^{\circ} / R T$

In Eqs. 12 and 13, $R$ value is $8.314 \mathrm{~J} / \mathrm{mol} \mathrm{K}$.

As shown in Supp. Table 1, the enthalpy change in the adsorption mechanisms for both of the adsorbents is exothermic. The adsorption of naproxen on M-MWCNT and $\mathrm{M}-\mathrm{AC}$ is spontaneous because the $\Delta \mathrm{G}^{\circ}$ values are negative. The $\Delta \mathrm{G}^{\circ}$ values of M-MWCNT vary between -6.47 and $-1.07 \mathrm{~kJ} / \mathrm{mol}$. The increasing temperature caused increase in $\Delta \mathrm{G}^{\circ}$ value. The same behavior can be seen in $\Delta \mathrm{G}^{\circ}$ values of M-AC. The $\Delta \mathrm{G}^{\circ}$ values vary between -3.37 and -1.00 . This result shows that the temperature increase decreases the spontaneity. The isotherm data show that the maximum uptake of adsorbents decreases while the temperature increases. The $\Delta \mathrm{S}^{\circ}$ values of M-MWCNT and M-AC are negative, too. According to $\Delta \mathrm{H}^{\circ}$ values, both of the adsorption processes are exothermic. $\Delta \mathrm{H}^{\circ}$ value of M-MWCNT is $-86.13 \mathrm{~kJ} / \mathrm{mol}$, and $\Delta \mathrm{H}^{\circ}$ value of M-MWCNT is $-38.02 \mathrm{~kJ} / \mathrm{mol}$. This result shows that while naproxen adsorbed on the adsorbents, randomness was decreased on the surface.

\section{Conclusion}

The M-MWCNT and M-AC were used for naproxen adsorption. For M-AC, the adsorption efficiency of naproxen reached $87.79 \%$ at $293 \mathrm{~K}$ and $\mathrm{pH}$ 5. The 
adsorption efficiency of M-MWCNT was $67.20 \%$ at $293 \mathrm{~K}$ and $\mathrm{pH}$ 3. The M-AC is more efficient adsorbent than M-MWCNT. The reason for this result is the difference in surface acidity. M-AC is more acidic than M-MWCNT. The naproxen behaves neutral as told above, so the adsorption capacity of M-AC is higher than of M-MWCNT. The thermodynamic behavior of both of the adsorbents is exothermic. Both of the adsorbents followed the Langmuir isotherm and pseudo-second-order models.

Acknowledgments We are grateful to the Board of Trustees of Beykent University for supplying chemicals and other equipment. We would like to thank Istanbul University Chemical Engineering Department for providing department facilities.

\section{References}

Ai L, Zhang C, Liao F, Wang Y, Li M, Meng L, Jiang J (2011) Removal of methylene blue from aqueous solution with magnetite loaded multi-wall carbon nanotube: kinetic, isotherm and mechanism analysis. J Hazard Mater 198:282-290

Attia TMS, Hu XL, Yin DQ (2013) Synthesized magnetic nanoparticles coated zeolite for the adsorption of pharmaceutical compounds from aqueous solution using batch and column studies. Chemosphere 93:2076-2085

Amin NK (2009) Removal of direct blue-106 dye from aqueous solution using new activated carbons developed from pomegranate peel: adsorption equilibrium and kinetics. J Hazard Mater 165:52-62

Baccar R, Sarrà M, Bouzid J, Feki M, Blánquez P (2012) Removal of pharmaceutical compounds by activated carbon prepared from agricultural by-product. Chem Eng J 211-212:310-317

Bayazit ŞS, Kerkez Ö (2014) Hexavalent chromium adsorption on superparamagnetic multi-wall carbon nanotubes and activated carbon composites. Chem Eng Res Des 92:2725-2733

Bui TX, Pham VH, Le ST, Choi H (2013) Adsorption of pharmaceuticals onto trimethylsilylated mesoporous SBA-15. J Hazard Mater 254-255:345-353

Do MH, Phan NH, Nguyen TD, Pham TTS, Nguyen VK, Vu TTT, Nguyen TKP (2011) Activated carbon/Fe3O4 nanoparticle composite: fabrication, methyl orange removal and regeneration by hydrogen peroxide. Chemosphere 85:1269-1276

Domínguez JR, González T, Palo P, Cuerda-Correa EM (2011) Removal of common pharmaceuticals present in surface waters by Amberlite XAD-7 acrylic-ester-resin: influence of $\mathrm{pH}$ and presence of other drugs. Desalination 269:231-238

Domínguez-Vargas JR, Gonzalez T, Palo P, Cuerda-Correa EM (2013) Removal of carbamazepine, naproxen, and trimethoprim from water by Amberlite XAD-7: a kinetic study. Clean Soil Air Water 41:1052-1061

Dubinin MMRLV, Radushkevich LV (1947) Equation of the characteristic curve of activated charcoal. Chem Zent 1:875
Elwakeel KZ (2014) Removal of arsenate from aqueous media by magnetic chitosan resin immobilized with molybdate oxoanions. Int J Environ Sci Technol 11:1051-1062

Freundlich H (1906) Adsorption in solids. Z Phys Chem 57:385-470

Ghaedi M, Haghdoust S, Kokhdan SN, Mihandoost A, Sahraie R, Daneshfar A (2012) Comparison of activated carbon, multiwalled carbon nanotubes, and cadmium hydroxide nanowire loaded on activated carbon as adsorbents for kinetic and equilibrium study of removal of Safranine O. Spectrosc Lett 45:500-510

Ghosh S, Badruddoza AZM, Hidajat K, Uddin MS (2013) Adsorptive removal of emerging contaminants from water using superparamagnetic $\mathrm{Fe} 3 \mathrm{O} 4$ nanoparticles bearing aminated $\beta$-cyclodextrin. J Environ Chem Eng 1:122-130

Hasan Z, Jeon J, Jhung SH (2012) Adsorptive removal of naproxen and clofibric acid from water using metal-organic frameworks. J Hazard Mater 209-210:151-157

Hasan Z, Choi E-J, Jhung SH (2013) Adsorption of naproxen and clofibric acid over a metal-organic framework MIL-101 functionalized with acidic and basic groups. Chem Eng J 219:537-544

Ho YS, McKay G (1999) Pseudo-second order model for sorption processes. Process Biochem 34:451-465

Hosseini F, Sadjadi MS, Farhadyar N (2014) Fe3O4 nanoparticles modified with APTES as the carrier for $(+)-(\mathrm{S})-2-(6-$ methoxynapthalen-2-yl) propanoic acid (Naproxen) and (RS) 2-(3benzoylphenyl)-propionic acid (Ketoprofen) drug. Orient $\mathrm{J}$ Chem 30(4):1609-1618

Im J-K et al (2013) Ultrasonic degradation of acetaminophen and naproxen in the presence of single-walled carbon nanotubes. J Hazard Mater 254-255:284-292

Kümmerer K (2001) Drugs in the environment: emission of drugs, diagnostic aids and disinfectants into wastewater by hospitals in relation to other sources-a review. Chemosphere 45:957-969

Lagergren S (1898) Zur theorie der sogenennten adsorption geloster stoffe. K Sven Vetenskapsakad Handl 24:1-39

Langmuir I (1918) The adsorption of gases on plane surfaces of glass, mica and platinum. J Am Chem Soc 40:1361-1403

Lü J, Feng L, Zhang L (2012) Adsorption of trace naproxen in waterby different activated carbons. Acta Sci Circum 32:2443-2449

Namvari M, Namazi H (2014) Clicking graphene oxide and Fe3O4 nanoparticles together: an efficient adsorbent to remove dyes from aqueous solutions. Int J Environ Sci Technol 11:1527-1536

Nethaji S, Sivasamy A, Mandal AB (2013) Preparation and characterization of corn cob activated carbon coated with nano-sized magnetite particles for the removal of $\mathrm{Cr}(\mathrm{VI})$. Bioresource Technol 134:94-100

Qiu H, Lv L, Pan B, Zhang Q, Zhang W, Zhang Q (2009) Critical review in adsorption kinetic models. J Zhejiang Univ Sci A 10:716-724

Qu S, Wang J, Kong J, Yang P, Chen G (2007) Magnetic loading of carbon nanotube/nano-Fe3O4 composite for electrochemical sensing. Talanta 71:1096-1102

Rivera-Utrilla J, Sánchez-Polo M, Ferro-García MÁ, Prados-Joya G, Ocampo-Pérez R (2013) Pharmaceuticals as emerging contaminants and their removal from water. A review. Chemosphere 93:1268-1287

Shariati S, Faraji M, Yamini Y, Rajabi AA (2011) Fe3O4 magnetic nanoparticles modified with sodium dodecyl sulfate for removal 
of safranin $\mathrm{O}$ dye from aqueous solutions. Desalination 270:160-165

Tütem E, Apak R, Ünal ÇF (1998) Adsorptive removal of chlorophenols from water by bituminous shale. Water Res 32:2315-2324

Weber WJ, Morris JC (1963) Kinetics of adsorption on carbon from solution. J Santi Eng Div ASCE 89:31-59
$\mathrm{Xu} \mathrm{P}$ et al (2012) Use of iron oxide nanomaterials in wastewater treatment: a review. Sci Total Environ 424:1-10

Yang H et al (2014) Magnetically recoverable iron oxide-hydroxyapatite nanocomposites for lead removal. Int $\mathrm{J}$ Environ Sci Technol 1-10. doi:10.1007/s13762-014-0514-2 